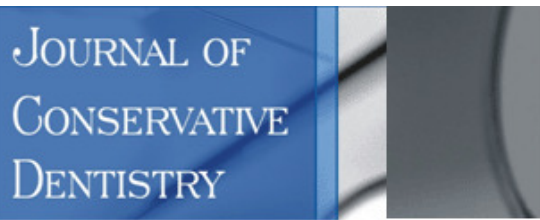

\author{
ORIGINAL ARTICLE \\ Year : 2016 | Volume : 19 | Issue : 1 | Page : 96--100
}

\title{
The effects of chlorhexidine and ethanol on push-out bond strength of fiber posts
}

Keli Regina Victorino ${ }^{1}$, Milton Carlos Kuga ${ }^{2}$, Marco Antonio Hungaro Duarte ${ }^{3}$, Bruno Cavalini Cavenago ${ }^{3}$, Marcus Vinicius Reis Só ${ }^{4}$, Jefferson Ricardo Pereira ${ }^{5}$

${ }^{1}$ Department of Endodontics, Araraquara Dental School, São Paulo State University, Araraquara, Brazil

2 Department of Restorative Dentistry, Araraquara Dental School, São Paulo State University, Araraquara, Brazil

3 Department of Endodontics, Bauru Dental School, University of São Paulo, Bauru, São Paulo, Brazil

${ }^{4}$ Department of Conservative Dentistry, Federal University of Rio Grande do Sul, Rio Grande do Sul, Brazil

5 Department of Prosthodontics, Dental School, University of Southern Santa Catarina, Tubarão, Santa Catarina, Brazil

Correspondence Address:

Jefferson Ricardo Pereira

Rua Recife 200 - Apto 601 - Bairro: Recife, Tubarão/SC, CEP - 88701-420

Brazil

\section{Abstract}

Context: Irrigation of root canals with chlorhexidine $(\mathrm{CHX})$ and ethanol is common practice to prevent root canal infection during postplacement. However, pretreatment with these solvents may interfere with the bond strength of posts. Aims: This study aimed to evaluate if root dentin pretreatment using $\mathrm{CHX}$ and/or ethanol influences the push-out bond strength of fiber-reinforced composite resin (FRCR) posts. Materials and Methods: Fifty space posts prepared in endodontically treated extracted human canine roots were randomly divided into five groups $(n=10)$ according to the dentin pretreatment: Distilled water $(W) ; 1 \% \mathrm{CHX}$ diacetate solution (1C); $\mathrm{CHX}$ diacetate $+99 \%$ ethanol $(1 \mathrm{CE}) ; 99 \%$ ethanol $(\mathrm{E})$; and $2 \% \mathrm{CHX}$ digluconate solution (2C). After pretreatment, the adhesive system (Peak Universal Bond; Ultradent, South Jordan, UT, USA) was applied in the root dentin and the FRCR was cemented with resin cement. Then, horizontal slices of $2 \mathrm{~mm}$ were obtained from each root third and the push-out bond strength was assessed. Statistical analysis was done using analysis of variance (ANOVA) and Tukey «SQ"S tests $(P=0.05)$. Results: At all thirds, $1 \mathrm{CE}$ and $\mathrm{E}$ groups presented similar push-out bond strength values $(P>0.05)$, which were higher than the other groups $(P<0.05)$. W, $1 C$, and $2 C$ groups were similar $(P>0.05)$. Conclusion: The root dentin pretreatment with ethanol, alone or mixed with $\mathrm{CHX}$ diacetate increased the bond strength of FRCR luted with resin cement.

How to cite this article:

Victorino KR, Kuga MC, Duarte MA, Cavenago BC, Só MV, Pereira JR. The effects of chlorhexidine and ethanol on push-out bond strength of fiber posts.J Conserv Dent 2016;19:96-100

How to cite this URL:

Victorino KR, Kuga MC, Duarte MA, Cavenago BC, Só MV, Pereira JR. The effects of chlorhexidine and ethanol on push-out bond strength of fiber posts. J Conserv Dent [serial online] 2016 [cited 2016 Mar 23 ];19:96-100

Available from: http://www.jcd.org.in/text.asp?2016/19/1/96/173210

\section{Full Text}

\section{INTRODUCTION}

Fiber-reinforced composite resin (FRCR) posts are routinely used in endodontically treated teeth with excessive loss of coronal structure. [1],[2] In terms of its main functions, FRCR provides core retention and transfers loads to the root in order to protect the tooth against root fracture. [3] FRCR does not corrode and its flexural modulus is closer to the dentin. [4]

This prefabricated post was proposed to be cemented into the root canal, but several factors may affect its retention, such as adhesive and cement system, type of post and post space adaptation, dentin pretreatment, and operative procedures. [1],[5] Therefore, it is essential to provide adequate adhesion among dentin, resin cement, and fiber post surfaces. [6] However, the dentin-resin interface adhesion can be compromised by the degradation of the adhesive system components due to water absorption and/or by proteolytic degradation of the hybrid layer, which is related to metalloproteinase action, [7],[8],[9] and by cysteine cathepsins. [10],[11]

The polar solvents used in hydrophilic etch-and-rinse adhesives remove water and cause shrinkage of the collagen matrix. [12] On the other hand, pretreatment of the water-saturated collagen matrix with ethanol achieves similar results but prevents phase separation of hydrophobic resin monomers such as bisphenol A glycidyl methacrylate (BisGMA). [13] Therefore, wet-bonding with ethanol provides a condition for coaxing hydrophobic monomers into a demineralized collagen matrix without compromising any additional matrix shrinkage. Penetration of hydrophobic monomers into a collagen matrix decreases water solubility and enzyme-catalyzed hydrolytic cleavage of collagen, creating more durable resin bonds [8],[14],[15],[16] and preserving the bond strength of FRCR cemented with resin cement for 12 months. [5]

Another procedure that can increase the longevity of the resin-dentin bond strength is the application of matrix metalloproteinase (MMP) inhibitors to the demineralized collagen matrix prior to application to the dentin. [9],[11] Chlorhexidine (CHX) has been applied to inhibit the activities of MMP-2, MMP-8, and MMP-9, [17] and likewise used as a nonspecific MMP inhibitor during the adhesive application. [9],[18],[19],[20],[21] CHX is effective for reducing degradation of resin-dentin bonds after in vivo aging [19],[22],[23] and in preserving the bond strength of FRCR similar to the effects of ethanol. [7]

The infiltration of hydrophobic resins facilitated by ethanol and the presence of MMP inhibitors within the hybrid layer would build the ideal interface and make it resistant to hydrolysis and enzymatic activities. [13] The association of ethanol and/or $\mathrm{CHX}$ can be used to prevent a reduction in bond strength values when using FRCR cemented with resin cement. [7] Studies [24],[25],[26],[27],[28] with different protocols of root dentin pretreatment have been conducted. However, there are no studies that evaluate the effects of $\mathrm{CHX}$ diacetate associated with ethanol on the bond strength of FRCR in human dentin.

The purpose of this study was to investigate the effects of dentin pretreatment by $\mathrm{CHX}$ diacetate and ethanol, alone or mixed, on the bond strength of the FRCR cemented with resin cement, in different root thirds, (cervical, medial, and apical). The null hypothesis is that the different dentin pretreatment agents have no effect on retention of FRCR posts cemented with resin cement in radicular dentin.

\section{Materials and Methods}


solution, at $4{ }^{\circ} \mathrm{C}$, and were cut at the cement-enamel junction with a diamond-coated saw (Isomet 2000; Buehler Ltd, Lake Bluff, IL, USA). The roots were adjusted to 16 mm in length and the working length was established $1 \mathrm{~mm}$ short of the apex. The root apices were sealed with composite resin (Z100 B2; 3M ESPE, St Paul, MN, USA).

All the root canals were instrumented using ProTaper rotary instruments (Dentsply Maillefer, Ballaigues, Switzerland), according to the manufacturer's recommendation. The master apical instrument was the ProTaper F5. Five milliliters of 2.5\% sodium hypochlorite (Asfer, São Caetano do Sul, SP, Brazil) was used for irrigation between each instrumentation with a final rinse of $2 \mathrm{~mL} 17 \%$ ethylenediaminetetraacetic acid (EDTA) for $1 \mathrm{~min}$, followed by $5 \mathrm{~mL}$ of $2.5 \%$ sodium hypochlorite. Each root canal was dried with paper points (Dentsply, York, PA, USA) and filled with the single-cone gutta-percha technique [24] and AH Plus sealer (DeTrey Dentsply, York, PA, USA). The teeth were stored at $37^{\circ} \mathrm{C}$ and $100 \%$ humidity for 7 days to allow for the setting of the sealer.

All the root canals were enlarged with a \#2 Unicore Drill (Ultradent, South Jordan, UT, USA), using a low-hand piece, to a depth of $11 \mathrm{~mm}$. During preparation of the canal, $4 \mathrm{~mm}$ of the endodontic filling was left at the apex of each canal. In sequence, all samples received a final rinse with $5 \mathrm{~mL}$ of distilled water and the excess was removed using paper points. The root canal dentin was prepared by etching the canal with $35 \%$ phosphoric acid solution (Ultra-Etch, Ultradent, South Jordan, UT, USA) for $20 \mathrm{~s}$, rinsed with water, blotting the excess water with paper points, and then randomly divided into five groups according to the dentin pretreatment protocol used $(n=10)$, as follows. Group W (control): The roots were irrigated with 2 $\mathrm{mL}$ distilled water; Group 1C: The root canals were filled with $2 \mathrm{~mL} \mathrm{1 \%} \mathrm{CHX} \mathrm{diacetate} \mathrm{solution} \mathrm{(Sigma-Aldrich,} \mathrm{St} \mathrm{Louis,} \mathrm{MO,} \mathrm{USA);} \mathrm{Group} \mathrm{1CE:} \mathrm{The} \mathrm{root} \mathrm{canals} \mathrm{were} \mathrm{filled} \mathrm{with} 2 \mathrm{~mL}$ CHX diacetate (Sigma-Aldrich, St Louis, MO, USA) mixed with $99 \%$ ethanol (Sigma-Aldrich, St Louis, MO, USA), in a proportion of $0.19 \mathrm{~g} / 25 \mathrm{~mL}$; Group E: The roots canals were filled with $2 \mathrm{~mL}$ 99\% ethanol (Sigma-Aldrich, St Louis, MO, USA); and Group 2C: The root canals were filled with $2 \mathrm{~mL} \%$ CHX digluconate solution (Concepsis, Ultradent, South Jordan, UT, USA). All solutions were maintained in the root canals for $60 \mathrm{~s}$ and dried with paper points.

An adhesive system (Peak Universal Bond, Ultradent, South Jordan, UT, USA) was applied to the root canal dentin according to the manufacturer's instructions and light-cured for $20 \mathrm{~s}$ using a halogen light-curing unit operated at in $1,000 \mathrm{~mW} / \mathrm{cm} 2$ (TM Ortholux LED Curing Light, 3M ESPE, St Paul, MN, USA). The automix system dual-cured resin luting cement (PermaFlo DC, Ultradent, South Jordan, UT, USA) was injected into the prepared root canal according to the manufacturer's instructions. In sequence, the FRCR (Unicore Post, Ultradent, South Jordan, UT, USA), size 2, was cleaned with $99 \%$ ethanol for $30 \mathrm{~s}$, and posts were cemented in the post space and kept under finger pressure for $30 \mathrm{~s}$, and the excess was removed. The resin cement was light-cured for $60 \mathrm{~s}$ on each root surface, totaling a 4-min light-curing cycle, using the same unit previously described. All specimens were maintained in $100 \%$ humidity, for $24 \mathrm{~h}$, at $37^{\circ} \mathrm{C}$.

Each root was then cut horizontally to the longitudinal axis using a low-speed diamond-coated saw (Isomet 2000, Buehler Ltd, Lake Bluff, IL, USA) under water cooling. Three slices were prepared at a thickness of $2 \mathrm{~mm}$ in the coronal, middle, and apical third of each root, which were taken respectively $1 \mathrm{~mm}, 5 \mathrm{~mm}$, and $8 \mathrm{~mm}$ from the cement-enamel junction. The push-out technique was performed by applying a load using an electromechanical testing machine (EMIC, DL2000, São José dos Pinhais, PR, Brasil), at $0.5 \mathrm{~mm} /$ min in the apex in the direction of the crown until the fiber postresin cement segment was dislodged from the root slice. A cylindrical plunger was used to dislodge with $1.3 \mathrm{~mm}, 0.9 \mathrm{~mm}$, and $0.5 \mathrm{~mm}$ diameters to the coronal, medial, and apical thirds, respectively.

To obtain the push-out bond strength in megapascal (MPa), the ultimate load at failure recorded in newtons (N) was divided by the area (mm 2 ) of the postdentin interface. [6] To calculate the bonding area, the upper and lower diameters of each slice were measured at 20x magnification with a stereomicroscope (Leica Microsystems Wetzlar GmbH, Wetzlar, Germany) and the formula described by Sagsen et al. [25] was applied. The dates were submitted to the Shapiro-Wilk test to verify the normal distribution. Thus, the mean and standard deviations of the push-out bond strength were calculated, and the data were analyzed using the one-way analysis of variance $(A N O V A)$ and Tukey's tests $(P=0.05)$.

After the push-out test, the slices were examined with a stereomicroscope at 20x magnification (Leica Microsystems Wetzlar GmbH, Wetzlar, Germany) to determine the failure pattern as: (AD) adhesive, between the dentin and resin cement; (MI) mixed; (PA) partially adhesive, between the FRCR and resin cement; or (CO) cohesive, at the resin cement, as described by Perdigão et al. [4]

\section{RESULTS}

The mean and standard deviation of the push-out bond strength (in MPa) at the coronal, medial, and apical root thirds are presented in [Table 1]. There was a significant difference ( $<<$ 0.05 ) among the groups. The groups in which dentin was pretreated with ethanol, alone or mixed with $\mathrm{CHX}$ diacetate, had significantly higher push-out bond strength values than the other groups, independently of the root thirds $(\mathrm{P}<0.05)$. Among the push-out bond strength values of the control group and dentin pretreated with $1 \% \mathrm{CHX}$ diacetate solution or $2 \% \mathrm{CHX}$ digluconate, there were no differences, independently of the root thirds $(P>0.05)$. $\{$ Table 1$\}$

Failure classification at the different thirds of the root canal is presented in [Table 2]. For the dentin pretreatment with ethanol, alone or mixed with $\mathrm{CHX}$ diacetate, there was a higher incidence of mixed failure. There was a higher incidence of adhesive failure for the other groups.\{Table 2\}

\section{DISCUSSION}

The purpose of this study was to evaluate the effects of dentin pretreatment by $\mathrm{CHX}$ diacetate and ethanol, alone or mixed, on the bond strength of FRCR luted with resin cement. The null hypothesis was rejected because different pretreatment dentin agents increased the bond strength of FRCR posts cemented with resin cement in radicular dentin.

The higher push-out bond strength obtained for the ethanol groups can be attributed to the best adhesion in the interface dentin-adhesive system, as ethanol is used to replace water prior to bonding, avoiding the collapse of the collagen matrix in the ethanol-wet bonding technique. The ethanol application can shrink the diameter of the dentin collagen fibrils [14] and consequently permit the infiltration of hydrophobic monomers to disperse into the demineralized dentin. [15] With larger interfibrillar spaces there is better penetration of monomers, providing higher shear bond strength values. [15],[16]

Cecchin et al. [5],[7] showed that ethanol used as a pretreatment in the root dentin did not provide an immediate higher bond strength of FRCR relined with composite resin using a self-etching or total etching system. When compared with the present study, a possible explanation for the different results is that the relined FRCR used by those authors presented higher push-out bond strength values than the nonrelined posts. Another factor is that the resin cement used presented a different chemical composition, which also affected the ultimate push-out bond strength values. [1],[3]

MMPs and cysteine cathepsins contribute to the degradation of collagen fibrils [11] within incompletely resin-infiltrated hybrid layers, reducing the mechanical properties of the collagen matrix. [13],[18] Thus, the use of MMP inhibitors prior to the application of dentin adhesives appears to be a rational step for extending the longevity of the hybrid layer. [9],[11],[12] CHX applied to the demineralized dentin prior to the application of an adhesive system has been shown to be effective for reducing degradation of the resin-dentin bonds. [20],[21],[23] However, the results of this study showed that $\mathrm{CHX}$ alone or with a diacetate or digluconate composition, used as a root dentin pretreatment, did not interfere with the immediate bond strength of FRCR luted with resinous cement. Despite the fact that CHX has effective MMP-inhibitory action, [13],[19],[23] its action has only been shown in a long-term period evaluation. [5] Therefore, it is possible that the short-term assessment and the time necessary for the root canal treatment may have influenced the results of the present study. This result is in accordance with previous studies [5],[7] in which it was observed that the use of $\mathrm{CHX}$ did not immediately negatively affect the push-out bond strength in the FRCR bond cementation but showed that its principal use is to preserve the adhesive-dentin bond for 12 months.

The mixed failure was the predominant factor when ethanol was used as a dentin pretreatment, alone or mixed with $\mathrm{CHX}$ diacetate, showing better adhesion in the dentin-adhesive system interface. Therefore, the dentin pretreatment with ethanol is interesting in terms of providing better adhesion of the adhesive system to root dentin. However, the result obtained in this study was simulated in the laboratory setting. Further studies to evaluate the long-term adhesion using these pretreatments are still required.

\section{CONCLUSION}


pretreatment with distilled water, $2 \% \mathrm{CHX}$ digluconate solution or $1 \% \mathrm{CHX}$ diacetate solution, independently of the root thirds, when analyzed in the short term.

Financial support and sponsorship

Nil.

Conflicts of interest

There are no conflicts of interest.

\section{References}

1 Pereira JR, Lins do Valle A, Ghizoni JS, Lorenzoni FC, Ramos MB, Dos Reis Só MV. Push-out bond strengths of different dental cements used to cement glass fiber posts. J Prosthet Dent 2013;110:134-40.

2 Franco EB, Lins do Valle A, Pompéia Fraga de Almeida AL, Rubo JH, Pereira JR. Fracture resistance of endodontically treated teeth restored with glass fiber posts of different lengths. J Prosthet Dent 2014;111:30-4.

Cheung W. A review of the management of endodontically treated teeth. Post, core and the final restoration. J Am Dent Assoc 2005;136:611-9.

Perdigão J, Geraldeli S, Lee IK. Push-out bond strengths of tooth-colored posts bonded with different adhesive systems. Am J Dent 2004;17: 422-6

Cecchin D, de Almeida JF, Gomes BP, Zaia AA, Ferraz CC. Effect of chlorhexidine and ethanol on the durability of the adhesion of the fiber post relined with resin composite to the root canal. J Endod 2011;37: 678-83.

Pereira JR, da Rosa RA, do Valle AL, Ghizoni JS, Só MV, Shiratori FK. The influence of different cements on the pull-out bond strength of fiber posts. J Prosthet Dent 2014;112:59-63.

7 Cecchin D, de Almeida JF, Gomes BP, Zaia AA, Ferraz CC. Influence of chlorhexidine and ethanol on the bond strength and durability of the adhesion of the fiber posts to root dentin using a total etching adhesive system. J Endod 2011;37:1310-5.

Malacarne J, Carvalho RM, de Goes MF, Svizero N, Pashley DH, Tay FR, et al. Water sorption/solubility of dental adhesive resins. Dent Mater 2006;22:973-80. Pashley DH, Tay FR, Yiu C, Hashimoto M, Breschi L, Carvalho RM, et al. Collagen degradation by host-derived enzymes during aging. J Dent Res 2004;83:216-21. Nascimento FD, Minciotti CL, Geraldeli S, Carrilho MR, Pashley DH, Tay FR, et al. Cysteine cathepsins in human carious dentin. J Dent Res 2011;90:506-11. Tersariol IL, Geraldeli S, Minciotti CL, Nascimento FD, Paakkonen V, Martins MT, et al. Cysteine cathepsins in human dentin-pulp complex. J Endod 2010;36:475-81. Pashley DH, Tay FR, Carvalho RM, Rueggeberg FA, Agee KA, Carrilho M, et al. From dry bonding to water-wet bonding to ethanol-wet bonding. A review of the interactions between dentin matrix and solvated resins using a macromodel of the hybrid layer. Am J Dent 2007;20:7-20.

13 Liu Y, Tjäderhane L, Breschi L, Mazzoni A, Li N, Mao J, et al. Limitations in bonding to dentin and experimental strategies to prevent bond degradation. J Dent Res $2011 ; 90: 953-68$.

14 Gendron R, Grenier D, Sorsa T, Mayrand D. Inhibition of the activities of matrix metalloproteinases 2, 8, and 9 by chlorhexidine. Clin Diagn Lab Immunol 1999;6:437-9. Carrilho MR, Carvalho RM, de Goes MF, di Hipólito V, Geraldeli S, Tay FR, et al. Chlorhexidine preserves dentin bond in vitro. J Dent Res 2007;86:90-4. Hebling J, Pashley DH, Tjaderhane L, Tay FR. Chlorhexidine arrests subclinical degradation of dentin hybrid layers in vivo. J Dent Res 2005;84:741-6. Mohammadi Z, Abbott PV. The properties and applications of chlorhexidine in endodontics. Int Endod J 2009;42:288-302.

Ricci HA, Sanabe ME, de Souza Costa CA, Pashley DH, Hebling J. Chlorhexidine increases the longevity of in vivo resin-dentin bonds. Eur J Oral Sci 2010;118:411-6. Breschi L, Mazzoni A, Nato F, Carrilho M, Visintini E, Tjaderhane L, et al. Chlorhexidine stabilizes the adhesive interface: A 2-year in vitro study. Dent Mater 2010;26:320-5. Carrilho MR, Geraldeli S, Tay F, de Goes MF, Carvalho RM, Tjaderhane L, et al. In vivo preservation of the hybrid layer by chlorhexidine. J Dent Res 2007;86:529-33. Rodrigues A, Bonetti-Filho I, Faria G, Andolfatto C, Camargo Vilella Berbert FL, Kuga MC. Percentage of gutta-percha in mesial canals of mandibular molars obturated by lateral compaction or single cone techniques. Microsc Res Tech 2012;75:1229-32.

Sagsen B, Ustün Y, Demirbuga S, Pala K. Push-out bond strength of two new calcium silicate-based endodontic sealers to root canal dentine. Int Endod J 2011;44:1088-91. Osorio E, Toledano M, Aguilera FS, Tay FR, Osorio R. Ethanol wet-bonding technique sensitivity assessed by AFM. J Dent Res 2010; 89:1264-9.

Pei D, Huang X, Huang C, Wang Y, Ouyang X, Zhang J. Ethanol-wet bonding may improve root dentine bonding performance of hydrophobic adhesive. J Dent 2012;40:433-41. Duan SS, Ouyang XB, Pei DD, Huo YH, Pan QH, Huang C. Effects of ethanol-wet bonding technique on root dentine adhesion. Chin J Dent Res 2011;14:105-11.

Gulati S, Shenoy VU, Margasahayam SV. Comparison of shear bond strength of resin-modified glass ionomer to conditioned and unconditioned mineral trioxide aggregate surface: An in vitro study. J Conserv Dent 2014;17:440-3.

27 Agrawal R, Tyagi SP, Nagpal R, Mishra CC, Singh UP. Effect of different root canal irrigants on the sealing ability of two all-in-one self-etch adhesives: An in vitro study. J Conserv Dent 2012;15: 377-82.

28 Mathew ST, Hegde MN. Shear bond strength of eugenol- and non-eugenol-based endodontic sealers to gutta-percha and dentin: An in vitro study. J Conserv Dent 2008;11:30-6. 